\title{
Induction of a reduction in haemoglobin concentration by enalapril in stable, moderate heart failure: a double blind study
}

\author{
Bo Herrlin, Olof Nyquist, Christer Sylvén
}

\begin{abstract}
Objective-To study the long term effects (12 weeks) of enalapril on central haemodynamic function and on arterial oxygen content and its determinantshaemoglobin concentration and oxygen saturation-in patients with stable moderate heart failure.

Design-Double blind placebo controlled randomised study.

Patients-17 patients with stable moderate heart failure caused by dilated cardiomyopathy which was treated with diuretics and digoxin.
\end{abstract}

Methods-Central haemodynamic function, arterial oxygen content, arterial haemoglobin concentration, and arterial oxygen saturation were measured at rest and during submaximal exercise. Plasma volume and total body haemoglobin were determined at rest.

Results-With enalapril treatment heart rate, pulmonary capillary wedge pressure, mean arterial pressure, and systemic vascular resistance decreased significantly both at rest and during submaximal exercise. Cardiac output did not change at rest but tended to increase $(p=0.06)$ during submaximal exercise. Arterial oxygen saturation remained unchanged while haemoglobin concentration and arterial oxygen content were significantly reduced. Total body haemoglobin was significantly reduced but the plasma volume remained unchanged. At rest, the reduction in arterial oxygen content resulted in a significantly reduced mixed venous oxygen content. However, during submaximal exercise the increase in cardiac output fully compensated for the reduction in arterial oxygen content and this effect was indicated by the unaltered mixed venous oxygen content. No changes were found in the placebo group after twelve weeks.

Conclusions-Enalapril unloads the heart and reduces haemoglobin concentration. During submaximal exercise, the improvement in systemic blood flow was counterbalanced by this negative effect on the oxygen carrying capacity and systemic oxygen delivery was unchanged.
In heart failure the capacity of cardiac output to increase during exercise is impaired and this reduces the systemic delivery of oxygen. Long term treatment with angiotensin converting enzyme inhibitors can improve cardiac output both at rest and during exercise $e^{1-3}$ but the effects of the treatment on arterial oxygen content are not known.

Erythropoietin, an important regulator of erythropoiesis, is mainly produced in the kidney. ${ }^{4}$ There is evidence that the reninangiotensin system modulates, directly or indirectly, the release of this hormone..$^{5-7}$ Studies have also shown that angiotensin converting enzyme inhibition exacerbates anaemia in chronic haemodialysis patients with hypertension ${ }^{8}$ and lowers the haematocrit in hypertension. ${ }^{9}$

The purpose of this double blind placebo controlled randomised study was to determine whether long term angiotensin converting enzyme inhibition with enalapril has any influence on the haemoglobin concentration and to evaluate the effect on systemic oxygen delivery both at rest and during submaximal exercise in a homogeneous group of patients with stable moderate heart failure caused by dilated cardiomyopathy.

\section{Patients and methods}

PATIENTS

We studied 19 patients (16 men and three women (41-62 years old (mean (SD)) 51 (6) years)) with moderate heart failure caused by dilated cardiomyopathy, which was treated with digoxin and frusemide. None of the patients had oedema and all had been clinically stable for at least two weeks. Inclusion criteria were an echocardiographically determined left ventricular end diastolic diameter of $>60$ and $>30 \mathrm{~mm} / \mathrm{m}^{2}$, a left ventricular shortening fraction of $<20 \%$, and an exercise capacity of $>$ stage III and $<$ IX, according to a revised Naughton protocol. ${ }^{10}$ We excluded patients with primary valve disease, suspected ischaemic heart disease or congenital valve disease, those taking concomitant vasodilating agents, and those with right sided heart failure caused by pulmonary disease. The study protocol was approved by the local ethics committee. All patients gave their informed consent before entering the study. 
PROTOCOL

The patient was admitted to hospital. The daily doses of digoxin and frusemide remained unchanged during the baseline study period before randomisation. On the first day the blood volume, venous haematocrit, venous haemoglobin concentration, serum potassium, and serum sodium were determined and echocardiography, a chest $x$ ray, and a symptom limited exercise test were performed. The total blood volume was measured by the ${ }^{131} I$-labelled serum albumin method. The haematocrit and haemoglobin concentration were determined in venous blood from an antecubital vein Echocardiography was performed on patients in the left lateral position (ATL Mark III, 13 $\mathrm{mm}$ and $3 \mathrm{MHz}$ transducer). Left ventricular end diastolic and end systolic diameters were measured. ${ }^{11}$ The mean value of five consecutive beats was calculated. The left ventricular shortening fraction was derived from the difference between left ventricular end diastolic and end systolic diameters divided by left ventricular end diastolic diameter. Cardiac volume was measured radiologically by Jonsell's method. ${ }^{12}$ Patients performed the exercise test sitting on an electrically braked ergometer. The load was increased every two minutes according to a modified Naughton protocol ${ }^{10}$ :

\begin{tabular}{llllllllll}
\multicolumn{10}{c}{ Stage } \\
W & $I$ & $I I$ & $I I I$ & $I V$ & $V$ & $V I$ & $V I I$ & $V I I I$ & $I X$ \\
10 & 20 & 30 & 50 & 70 & 90 & 110 & 130 & 150
\end{tabular}

The patients exercised until limiting symptoms developed-that is dyspnoea or fatigue or both. Perceived exertion was rated on the scale designed by Borg. ${ }^{13}$

On the second day the patient was made familiar with the catheterisation laboratory and with the ergometer on the catheterisation table. Patients chose the highest load that they believed they could maintain for 10 minutes in the supine position. This was used as the submaximal load during the cardiac catheterisation. On the second day renal plasma flow was determined by $p$-aminohippurate and creatinine clearance was calculated from 24 hour urine collections and serum creatinine. The reference values in healthy subjects were $500-800 \mathrm{ml} / \mathrm{min}$ and $85-145 \mathrm{ml} / \mathrm{min}$ respectively.

On the third day, at $5.30 \mathrm{am}$, the patient was given a light breakfast and his or her daily dose of digoxin and frusemide. The right ventricle was catheterised at 8 am. A triple lumen balloon tipped thermodilution catheter (Edwards Laboratory, USA) was introduced via an antecubital or femoral vein under fluoroscopic guidance and was used to measure right atrial, pulmonary arterial, and pulmonary capillary wedge pressures. A polyethylene arterial catheter was introduced into the brachial or femoral artery to measure the systemic pressure. The measurements of haemodynamic function were made with the zero reference level at the mid-axillary line. Cardiac output was measured by a cardiac output computer (Cardiac Computer, Edwards Laboratories, model 9520) with the use of an iced injectate. Heart rate was derived from a continuously recorded electrocardiogram. Blood was taken from the pulmonary artery lumen of the Swan-Ganz catheter for mixed venous samples and from the arterial catheter for arterial samples.

After about 30 minutes of rest haemodynamic recordings were performed and samples of arterial blood were taken to measure blood gases, blood lactate, and plasma noradrenaline. Samples of arterial blood and mixed venous blood were taken simultaneously for analyses of oxygen saturation and haemoglobin concentration. After three minutes of exercise pressures were determined according to the protocol and cardiac output was measured. After approximately six minutes of exercise blood samples were taken for the same determinations as before exercise.

After the exercise test the patient was randomised to placebo or $10 \mathrm{mg}$ enalapril twice a day by mouth. Then frequent samples were taken for 24 hours for blood measurements; this caused a significant decrease in haemoglobin concentration.

The patient was seen every two weeks for eight weeks. Haemoglobin concentration was determined in venous blood drawn from an antecubital vein. After 12 weeks the patient was admitted to hospital for a repeat study with the same workload as in the submaximal exercise test at baseline.

BLOOD ANALYSES

Blood lactate was analysed by a semiautomatic system based on flow injection analysis with a coefficient of variation of $4.9 \% .{ }^{14}$ Blood oxygen saturation and haemoglobin concentration were determined photometrically with an Osmo 2-Hemoximeter (Radiometer, Copenhagen). Plasma noradrenaline was measured by liquid chromatography with electrochemical detection. ${ }^{15}$ The upper reference limit in normal subjects at rest was $2 \cdot 3 \mathrm{nmol} / 1$.

\section{ANALYSES}

Mean right atrial pressure (RAP), mean pulmonary capillary wedge pressure (PCWP), and mean systemic arterial pressure (MAP) were determined by electronic integration. Cardiac output (CO) was determined in triplicate. Heart rate (HR) was determined for one minute. Derived variables were calculated as follows:

Systemic vascular resistance $=80 \times(\mathrm{MAP}-$ RAP)/CO (dyn.s. $\mathrm{cm}^{-5}$ ).

Blood oxygen content $=$ per cent oxygen saturation $x$ haemoglobin concentration $\times$ $1.34 \mathrm{ml}$ oxygen/haemoglobin $(\mathrm{ml} / \mathrm{l})$.

Arteriovenous oxygen difference $\left(\mathrm{AVO}_{2}\right)=$ arterial oxygen content - mixed venous oxygen content $(\mathrm{ml} / \mathrm{l})$.

Systemic oxygen delivery $=\mathrm{CO} \times$ arterial oxygen content $(\mathrm{ml} / \mathrm{min})$.

Oxygen uptake $\left(\mathrm{VO}_{2}\right)=\mathrm{AVo}_{2} \times \mathrm{CO} /$ body weight $(\mathrm{ml} / \mathrm{min} / \mathrm{kg})$.

Plasma volume $=$ blood volume $(1-0.88 \times$ venous haematocrit) (1). ${ }^{16}$

Total body haemoglobin $=$ blood volume $\times$ venous haemoglobin concentration $\times 0.91$ (g). ${ }^{17}$ 
Table 1 Clinical characteristics and non-invasive findings of patient groups at baseline

\begin{tabular}{|c|c|c|c|}
\hline Characteristic & $\begin{array}{l}\text { Placebo } \\
(n=9)\end{array}$ & $\begin{array}{l}\text { Ena } \\
(n=\end{array}$ & $\begin{array}{l}\text { april } \\
\text { 8) }\end{array}$ \\
\hline $\begin{array}{l}\text { Age }(y r) \\
\text { Sex }(F / M)\end{array}$ & ${ }_{1 / 9}^{53}(4)$ & & $8^{(6)}$ \\
\hline $\begin{array}{l}\text { Duration of symptoms (mnth): } \\
\text { Mean (SD) } \\
\text { Median (range) }\end{array}$ & $\begin{array}{ll}21 & (12) \\
17 & (6-36)\end{array}$ & $\begin{array}{l}38 \\
25\end{array}$ & $\begin{array}{l}(28) \\
(3-89)\end{array}$ \\
\hline $\begin{array}{l}\text { Symptom-limited exercise test } \\
\text { exercise duration (s) }\end{array}$ & $701 \quad(93)$ & 753 & (150) \\
\hline $\begin{array}{l}\text { Echocardiography: } \\
\text { LVEDD }(\mathrm{mm}) \\
\text { FS }(\%)\end{array}$ & $\begin{array}{ll}71 & (8) \\
11 & (4)\end{array}$ & $\begin{array}{l}78 \\
11\end{array}$ & $\begin{array}{l}(11) \\
(3)\end{array}$ \\
\hline $\begin{array}{l}\text { Chest } x \text { ray heart volume } \\
\left(\mathrm{ml} / \mathrm{m}^{2}\right)\end{array}$ & 712 (144) & 826 & (157) \\
\hline
\end{tabular}

Difference between groups were all non-significant

FS, left ventricular fractional shortening; LVEDD, left ventricular end diastolic diameter.

\section{STATISTICAL ANALYSIS}

Values are given as means (SD). Changes within groups were tested by paired $t$ tests. Unpaired $t$ tests were used to evaluate differences between two groups. Multiple comparisons of repeated measurements were tested by analysis of variance and Fisher's test for a protected least square significant difference. A p value $<0.05$ was regarded as significant.

\section{Results}

Table 1 shows the clinical characteristics and non-invasive findings. Nine patients were randomised to placebo and ten to enalapril $10 \mathrm{mg}$ twice a day. One patient on enalapril died suddenly after six weeks. During the study another patient on enalapril showed changes in haemoglobin concentration that were different from the remaining 17 patients. He showed the greatest absolute and relative changes in blood volume after 12 weeks compared with baseline (>2 SD compared with the remaining patients) and the greatest absolute and relative changes in haemoglobin concentration after 12 weeks compared with baseline, six weeks, and eight weeks $(>2 \mathrm{SD},>2 \mathrm{SD}$, and $>3 \mathrm{SD}$ respectively) compared with the 17 remaining patients. Values for this patient were therefore regarded as outliers reflecting unstable vascular homoeostasis. These two patients were excluded from further analysis. All patients completed the protocol without complications.

The frusemide dose was increased in two patients in the placebo group because of increased dyspnoea. During the first week the daily dose of frusemide was reduced in three patients in the enalapril group because of symptomatic hypotension and this reduced

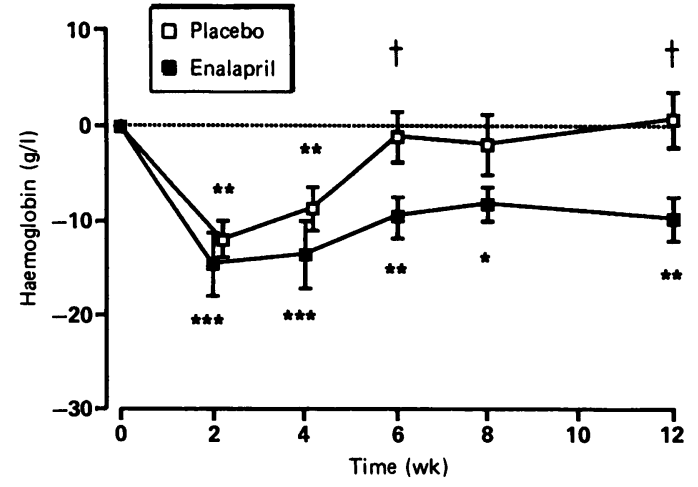

Figure 1 Absolute changes (mean (SEM)) in haemoglobin concentration in venous blood over 12 weeks. Differences within groups compared with baseline are indicated as ${ }^{*} p<0.05, \star \star p<0.01, \star \star \star p<0.001$ Differences in changes from baseline between groups are indicated as $+p<0.05$.

dose was maintained throughout the study period. None of the patients had peripheral oedema during the study and all had normal plasma sodium concentrations.

Body weight, blood volume, and plasma volume did not change in the two groups. Total body haemoglobin was reduced in the enalapril group but remained unchanged in the placebo group (table 2).

Creatinine clearance increased and renal plasma flow tended to increase $(+30(59) \%$, $\mathrm{p}<0 \cdot 10)$ with enalapril. Creatinine clearance increased considerably by $32(18) \mathrm{ml} / \mathrm{min}$ in the three patients in whom the dose of diuretics was reduced whereas in the remaining five patients it increased by 6 (11) $\mathrm{ml} / \mathrm{min}$. No changes were found in the placebo group. Serum creatinine (table 2), serum potassium, and serum sodium did not change in either group.

Exercise duration and perceived exertion during the symptom limited maximal exercise test remained unchanged in both groups (table 2).

\section{VENOUS HAEMOGLOBIN CONCENTRATION DURING} THE 12 WEEK STUDY

After two weeks, compared with baseline, the haemoglobin concentration was reduced in both groups (fig 1). With placebo at six weeks the haemoglobin concentration was restored to the baseline value and then remained unchanged. With enalapril the haemoglobin concentration was incompletely restored at six weeks and remained at a value significantly below baseline for the rest of the study period.

Table 2 Weight, blood volume, total body haemoglobin, renal function, and exercise capacity (mean (SD))

\begin{tabular}{|c|c|c|c|c|c|c|c|c|}
\hline \multirow{2}{*}{ Data } & \multicolumn{4}{|c|}{ Baseline } & \multicolumn{4}{|c|}{12 weeks } \\
\hline & \multicolumn{2}{|c|}{ Placebo $(n=9)$} & \multicolumn{2}{|c|}{ Enalapril $(n=8)$} & \multicolumn{2}{|c|}{ Placebo $(n=9)$} & \multicolumn{2}{|c|}{ Enalapril $(n=8)$} \\
\hline $\begin{array}{l}\text { Weight }(\mathrm{kg}) \\
\text { Blood volume }(\mathrm{l}) \\
\text { Plasma volume }(\mathrm{l}) \\
\text { Total body haemoglobin }(\mathrm{g}) \\
\text { Creatinine clearance }(\mathrm{ml} / \mathrm{min}) \\
\text { Renal plasma flow }(\mathrm{ml} / \mathrm{min}) \\
\text { Serum creatinine }(\mu \mathrm{mol} / \mathrm{l}) \\
\text { Exercise duration }(\mathrm{s}) \\
\text { Perceived exertion }\left(\text { Borg }^{13}\right)\end{array}$ & $\begin{array}{r}79 \\
5 \cdot 8 \\
3 \cdot 5 \\
779 \\
96 \\
390 \\
96 \\
701 \\
16\end{array}$ & $\begin{array}{l}(14) \\
(1 \cdot 4) \\
(0 \cdot 7) \\
(240) \\
(28) \\
(130) \\
(17) \\
(93) \\
(1)\end{array}$ & $\begin{array}{c}84 \\
6 \cdot 2 \\
3 \cdot 8 \\
880 \\
89 \\
349 \\
100 \\
753 \\
16\end{array}$ & $\begin{array}{l}(11) \\
(1 \cdot 0) \\
(0 \cdot 6) \\
(188) \\
(16) \\
(92) \\
(17) \\
(150) \\
(1)\end{array}$ & $\begin{array}{r}80 \\
5 \cdot 6 \\
3 \cdot 3 \\
756 \\
101 \\
427 \\
91 \\
650 \\
17\end{array}$ & $\begin{array}{l}(15) \\
(1 \cdot 3) \\
(0 \cdot 6) \\
(225) \\
(37) \\
(83) \\
(15) \\
(145) \\
(1)\end{array}$ & $\begin{array}{r}82 \\
6 \cdot 0 \\
3 \cdot 8 \\
782 \\
105 \\
416 \\
97 \\
753 \\
16\end{array}$ & $\begin{array}{l}(10) \\
(0 \cdot 8) \\
(0.5) \\
(135)^{\star} \\
(17)^{\star} \\
(99) \\
(17) \\
(164) \\
(1)\end{array}$ \\
\hline
\end{tabular}


Table 3 Haemodynamic, metabolic, and hormonal measurements (mean (SD))

\begin{tabular}{|c|c|c|c|c|c|c|c|c|}
\hline \multirow[b]{4}{*}{ 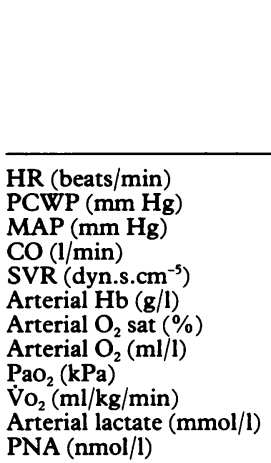 } & \multicolumn{8}{|l|}{ Rest } \\
\hline & \multicolumn{4}{|c|}{ Placebo $(n=9)$} & \multicolumn{4}{|c|}{ Enalapril $(n=8)$} \\
\hline & \multicolumn{2}{|c|}{ Baseline } & \multicolumn{2}{|c|}{12 weeks } & \multicolumn{2}{|c|}{ Baseline } & \multicolumn{2}{|c|}{12 weeks } \\
\hline & $\begin{array}{c}83 \\
13 \\
87 \\
4 \cdot 7 \\
1462 \\
147 \\
96 \\
192 \\
10 \cdot 9 \\
3 \cdot 7 \\
0 \cdot 8 \\
2 \cdot 7\end{array}$ & $\begin{array}{l}(14) \\
(7) \\
(11) \\
(0 \cdot 8) \\
(342) \\
(15) \\
(1) \\
(20) \\
(1 \cdot 3) \\
(0.8) \\
(0 \cdot 2) \\
(0.8)\end{array}$ & $\begin{array}{c}86 \\
11 \\
85 \\
4 \cdot 6 \\
1470 \\
147 \\
96 \\
190 \\
10 \cdot 6 \\
3.5 \\
0.9 \\
2.6\end{array}$ & $\begin{array}{l}(15) \\
(9) \\
(13) \\
(0 \cdot 7) \\
(404) \\
(18) \\
(2) \\
(24) \\
(1 \cdot 4) \\
(0 \cdot 6) \\
(0 \cdot 2) \\
(0 \cdot 8)\end{array}$ & $\begin{array}{c}91 \\
20 \\
92 \\
4 \cdot 4 \\
1609 \\
155 \\
97 \\
204 \\
11 \cdot 0 \\
4 \cdot 0 \\
0 \cdot 8 \\
3 \cdot 1\end{array}$ & $\begin{array}{l}(25) \\
(12) \\
(12) \\
(0 \cdot 8) \\
(305) \\
(11) \\
(1) \\
(14) \\
(0 \cdot 7) \\
(0 \cdot 6) \\
(0 \cdot 3) \\
(1 \cdot 4)\end{array}$ & $\begin{array}{c}79 \\
12 \\
75 \\
4 \cdot 5 \\
1311 \\
142 \\
98 \\
188 \\
12 \cdot 0 \\
3 \cdot 6 \\
0.9 \\
2 \cdot 2\end{array}$ & $\begin{array}{l}(16)^{\star \star \star \dagger} \\
(6)^{\star} \\
(8)^{\star \star \dagger} \\
(1 \cdot 1) \\
(315)^{\star} \dagger \\
(12)^{\star \star \dagger} \\
(1) \\
(14)^{\star \dagger} \\
(1 \cdot 1) \\
(0 \cdot 4) \\
(0 \cdot 3) \\
(0.9)^{\star \star \dagger}\end{array}$ \\
\hline
\end{tabular}

Differences compared with baseline within groups: ${ }^{\star} \mathrm{p}<0.05,{ }^{\star \star} \mathrm{p}<0.01,{ }^{\star \star \star} \mathrm{p}<0.001$.

Differences in change from baseline between groups: $t p<0.05, \pm p<0.01,+\dagger p<0.001$.

CO, cardiac output; HR, heart rate; MAP, mean arterial pressure; PCWP, pulmonary capillary wedge pressure; PNA, arterial

plasma noradrenaline; $S$ VR, systemic vascular resistance; $\dot{\mathrm{VO}}_{2}=$ oxygen uptake.

Haemoglobin concentration decreased by 7,7 , and $10 \mathrm{~g} / 1$ respectively in the three patients in whom the dose of diuretics was reduced, while in the remaining five patients it fell by $18(9) \mathrm{g} / \mathrm{l}$.

\section{HAEMODYNAMIC FUNCTION}

In the enalapril group-both at rest and during submaximal exercise-heart rate, pulmonary capillary wedge pressure, mean arterial pressure, and systemic vascular resistance were reduced (table 3 ). During submaximal exercise cardiac output tended to increase $(p=0.06)$. No changes were noted in the placebo group.

\section{OXYGEN TRANSPORT}

In the enalapril group haemoglobin concentration and arterial oxygen content were reduced while both arterial oxygen pressure and arterial oxygen saturation were unchanged (table 3 ). Systemic oxygen delivery was reduced at rest

Figure 2 Absolute changes (mean ( $S D)$ ) in blood oxygen content, compared with baseline, at rest and during

submaximal exercise. Differences within groups compared with baseline are indicated as ${ }^{\star} p<0.05$, $\star \star p<0.01$, and $\star \star \star x p<$ $0 \cdot 001$. Differences in changes from baseline between groups are indicated as $\dagger p<0.05$, $\dagger+p<0.01$, and $+\dagger \dagger p>$ 0.001 .
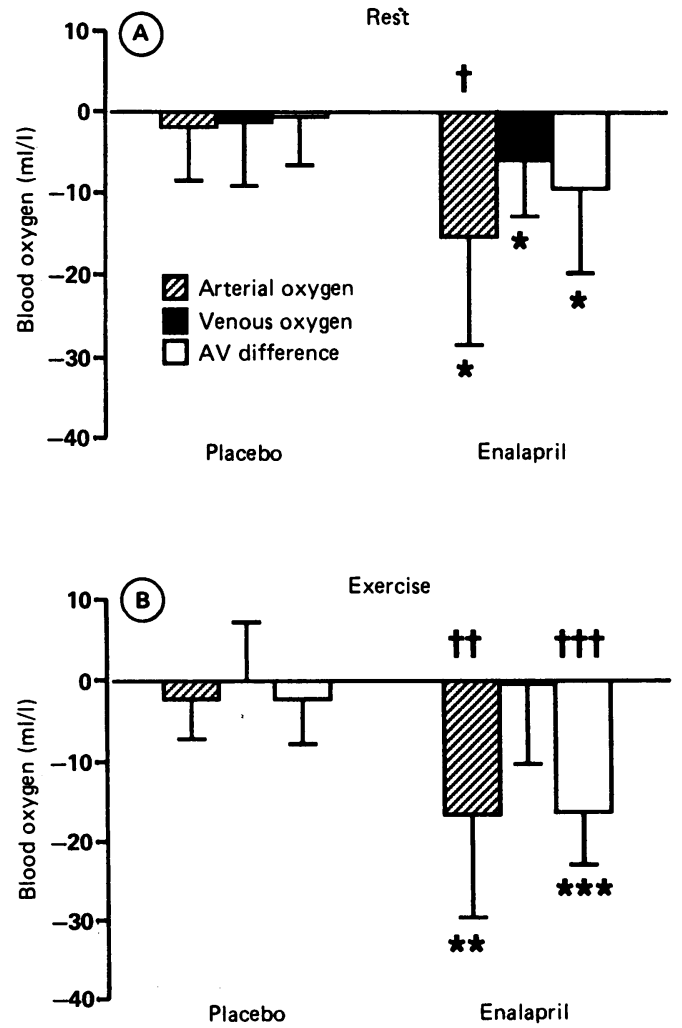

( $p<0.05$ ) but did not change during submaximal exercise. At rest both the mixed venous oxygen content and arteriovenous oxygen difference were reduced (fig 2A). During submaximal exercise the arteriovenous oxygen content was reduced by the same amount as the arterial oxygen content with no change in systemic oxygen delivery (fig $2 B$ ). There were no changes in the placebo group.

Oxygen uptake and arterial blood lactate remained unchanged in the two groups both at rest and during submaximal exercise. Plasma noradrenaline did not differ from baseline in the placebo group but was reduced both at rest and during submaximal exercise with enalapril (table 3).

\section{Discussion}

The present study showed that long term treatment with enalapril unloads the heart both at rest and during exercise, improves renal function, and induces a reduction in haemoglobin concentration and the total amount of haemoglobin in patients with stable, chronic, moderate heart failure caused by dilated cardiomyopathy. During submaximal exercise the reduction in arterial oxygen content counterbalanced the increased systemic blood flow and resulted in an unchanged delivery of systemic oxygen.

\section{COMPARISON WITH PREVIOUS STUDIES}

Several controlled long term studies of angiotensin converting enzyme inhibition in heart failure have reported symptomatic improvement ${ }^{318-20}$ However, the effect on exercise tolerance is variable. An increase in exercise duration compared with placebo ${ }^{318-21}$ or with baseline in the treatment group ${ }^{122}$ or lack of improvement ${ }^{23-25}$ have been reported. If exercise tolerance increases gradually ${ }^{1821}$ a study period of less than 12 weeks may be too short to show that treatment increases exercise duration. ${ }^{24}$ Increased daily activity resulting in peripheral conditioning may be important ${ }^{2627}$ and may explain the gradual improvement in exercise capacity. However, in the present long term study, both exercise duration and perceived exertion remained unchanged during 


\begin{tabular}{|c|c|c|c|c|c|c|c|}
\hline \multicolumn{8}{|c|}{ Exercise } \\
\hline \multicolumn{4}{|c|}{ Placebo $(n=9)$} & \multicolumn{4}{|c|}{ Enalapril $(n=8)$} \\
\hline \multicolumn{2}{|c|}{ Baseline } & \multicolumn{2}{|c|}{12 weeks } & \multicolumn{2}{|c|}{ Baseline } & \multicolumn{2}{|c|}{12 weeks } \\
\hline $\begin{array}{c}111 \\
24 \\
96 \\
7 \cdot 0 \\
1069 \\
152 \\
97 \\
201 \\
11 \cdot 5 \\
10 \cdot 3 \\
1.7 \\
4.6\end{array}$ & $\begin{array}{l}(20) \\
(12) \\
(12) \\
(1.5) \\
(295) \\
(16) \\
(1) \\
(21) \\
(0.8) \\
(1 \cdot 6) \\
(0.6) \\
(1.6)\end{array}$ & $\begin{array}{c}119 \\
24 \\
102 \\
7 \cdot 2 \\
1118 \\
151 \\
97 \\
198 \\
11 \cdot 3 \\
10 \cdot 4 \\
2 \cdot 1 \\
6 \cdot 0\end{array}$ & $\begin{array}{l}(25) \\
(13) \\
(13) \\
(1 \cdot 3) \\
(269) \\
(16) \\
(1) \\
(24) \\
(0.9) \\
(1.9) \\
(0.6) \\
(1.7)\end{array}$ & $\begin{array}{c}121 \\
31 \\
106 \\
6 \cdot 6 \\
1167 \\
159 \\
97 \\
212 \\
12 \cdot 2 \\
10 \cdot 4 \\
2 \cdot 1 \\
6 \cdot 4\end{array}$ & $\begin{array}{l}(22) \\
(10) \\
(13) \\
(1 \cdot 3) \\
(172) \\
(11) \\
(2) \\
(17) \\
(1 \cdot 8) \\
(1 \cdot 2) \\
(0 \cdot 7) \\
(3 \cdot 2)\end{array}$ & $\begin{array}{c}112 \\
22 \\
91 \\
7 \cdot 7 \\
886 \\
147 \\
97 \\
195 \\
12 \cdot 6 \\
10 \cdot 5 \\
2 \cdot 0 \\
4 \cdot 7\end{array}$ & $\begin{array}{l}(17)^{\star \star \star \dagger \dagger} \\
(7)^{\star \star \star \ddagger} \\
(21)^{\star \star \ddagger} \\
(1 \cdot 8)^{\star} \\
(202)^{\star \star \ddagger} \\
(10)^{\star \star \ddagger} \\
(2) \\
(15)^{\star \star \ddagger} \\
(1 \cdot 9) \\
(2 \cdot 7) \\
(0 \cdot 5) \\
(2 \cdot 3)^{\star}+\dagger\end{array}$ \\
\hline
\end{tabular}

the symptom limited maximal exercise test. Also, arterial blood lactate did not change during the submaximal exercise test. These findings indicate a lack of peripheral conditioning and a lack of increased oxidative capacity in working skeletal muscle. Our patients might have already conditioned themselves during routine daily activities to a high level of oxidative capacity in relation to their cardiac reserve. This would have limited their ability to improve their conditioning.

To date six double blind trials have reported haemodynamic effects both at rest and during exercise after long term angiotensin converting enzyme inhibition in heart failure. Important differences in study design make comparisons difficult. In three studies haemodynamic recordings were made with the patient in the supine position and at a submaximal workload 2829 whereas in the other three studies recordings were made with the patient in the upright position and/or at peak exercise. ${ }^{12425}$ In half of the studies diuretics were withheld on the day of investigation. ${ }^{2829}$ In the present study enalapril significantly unloaded the heart, which must have reduced the metabolic cost for the left ventricle. ${ }^{30}$ This finding is consistent with previous studies. ${ }^{24}{ }^{29}$ However, the highly significant changes from baseline in the present study suggest a more pronounced and beneficial haemodynamic response than in the earlier studies. Several factors could have contributed to these differences. Firstly, we used a higher daily dose of enalapril, which probably produced more complete converting enzyme inhibition than one in which only minor haemodynamic changes occurred. ${ }^{29}$ Secondly, our patients were given diuretics on the day of investigation and this may have potentiated the effects of enalapril owing to complex interactions between the diuretics and converting enzyme inhibitors. ${ }^{31}$ Thirdly, the reduction in haemoglobin concentration may lessen blood viscosity and total peripheral resistance. ${ }^{32}$ Finally, during exercise, reduced arterial oxygen content may induce a compensatory vasodilatation in skeletal muscle ${ }^{33}$ and thereby reduce systemic vascular resistance.

In previous studies the heterogeneity of patients-with heart failure or unstable vas- cular homoeostasis or both-and changes in plasma volume may have masked the effect of converting enzyme inhibition on haemoglobin concentration shown in this study. Furthermore, we studied our patients for long enough (probably a minimum of six weeks) to detect these changes. Similarly, rats treated with captopril showed a delay of recovery from haemorrhagic anaemia at six weeks. ${ }^{34}$

ERYTHROPOIESIS AND ANGIOTENSIN CONVERTING ENZYME INHIBITION

Erythropoietin regulates erythropoiesis and is mainly produced in the kidney. ${ }^{4}$ A reduced renal oxygen supply in anaemia and hypoxic hypoxia or renal hypoperfusion or both elicit oxygen sensing reactions that have been postulated to trigger the release of several mediators such as adenosine, prostaglandins, and cyclic AMP. These messenger molecules may stimulate the synthesis and release of erythropoietin. ${ }^{4}$ Also, changes in the ratio of renal oxygen demand to supply can affect erythropoietin release. Tubular sodium reabsorption is the predominant determinant of renal oxygen consumption. ${ }^{35}$ Reduced erythropoietin formation in response to normobaric hypoxia after inhibition of sodium reabsorption in the proximal tubule has been reported in an experimental study. ${ }^{36}$ This finding suggests that the function of the renal oxygen sensor is related to proximal tubular function.

Heart failure is characterised by increased plasma concentrations of noradrenaline which reflect increased overall sympathetic activity. Also, renal noradrenaline spillover is increased at rest and during exercise. ${ }^{37}$ Increased renal nerve sympathetic activity stimulates intrarenal release of prostaglandins and activates the renin-angiotensin system. ${ }^{38}$ Renal sympathetic nerves and angiotensin II interact functionally. ${ }^{39}$ Both induce changes in the renal microcirculation, causing reduced renal blood flow and redistribution from the cortex to the medulla. ${ }^{38}$ They may also directly and indirectly enhance sodium reabsorption by the proximal tubule. ${ }^{4041}$ Consequently, the oxygen supply/demand ratio may be altered in the renal cortex in heart failure. Such renal responses could stimulate erythropoietin production directly or indirectly. The reported high concentrations of erythropoietin in patients with congestive heart failure ${ }^{42}$ support this concept.

Converting enzyme inhibitors reduced the production of angiotensin II, and this resulted in attenuated sympathetic activity ${ }^{43}$ and an improved renal blood flow. ${ }^{40}$ These effects were confirmed in the present study. Enalapril induced a reduction in plasma noradrenaline both at rest and during submaximal exercise, which is consistent with a previous controlled study. ${ }^{44}$ This finding indicates reduced systemic, and probably also renal, sympathetic activity. ${ }^{37}$ The glomerular filtration rate, as determined by endogenous creatinine clearance, increased and the renal plasma flow tended to increase. However, renal plasma flow was determined at rest and not during daily activities. This it is not as representative of the 
24 hours as the endogenous creatinine clearance. Furthermore, both arterial oxygen pressure and arterial oxygen saturation were unchanged. Consequently, the attenuated erythropoiesis we saw after enalapril treatment may be due to changes in renal circulation and/ or hormone production and their modulation of erythropoietin release. This hypothesis is supported by a recent study in which high serum erythropoietin concentrations returned to normal during enalapril treatment of congestive heart failure. ${ }^{42}$

Functional renal insufficiency was reported during angiotensin converting enzyme inhibition in up to one third of salt-restricted patients with severe chronic heart failure and with constant dosages of diuretics. ${ }^{45}$ In two controlled studies Cleland and colleagues found that when sodium intake and diuretic dosage were kept constant the glomerular filtration fell considerably during treatment with captopril and enalapril. ${ }^{1920}$ In general their patients were not very hyponatraemic and they were not sodium restricted. Another large controlled study to compare lisinopril and captopril showed small increases in blood urea nitrogen and serum creatinine. ${ }^{46}$ These findings indicate that it is usual to see a fall in glomerular filtration rate when treatment with an angiotension converting enzyme inhibitor is started, but that in certain instances, as in the present study, this may not occur. In uncontrolled studies others reported little change or increases in the glomerular filtration rate when the dosage of diuretics was reduced or when the sodium intake was unrestricted. ${ }^{47-49}$ Similarly, in the present study, the improvement in the glomerular filtration rate in the enalapril group was attributable to the improvements in the three patients in whom the dose of diuretics was reduced.

Transient weight gain and plasma volume expansion have been reported soon after the start of treatment with converting enzyme inhibition. ${ }^{192050}$ However, during long term treatment there may be a progressive reduction in plasma volume..$^{50}$ In the present study plasma volume remained unchanged after 12 weeks, indicating that the reduction in haemoglobin concentration was not caused by plasma volume expansion.

In conclusion, the present study showed the complexity of the effects of angiotensin converting enzyme inhibition in heart failure. Enalapril unloaded the heart and improved renal function and the systemic blood flow. The increased systemic blood flow was, however, counterbalanced by an adaptive reduction in haemoglobin concentration and arterial oxygen carrying capacity, which resulted in an unchanged systemic oxygen delivery during submaximal exercise. Further, our findings underscore the importance of evaluating the effect of angiotensin converting enzyme inhibition in heart failure on haemoglobin concentration in haemodynamic long term intervention studies to avoid the effect on systemic or regional oxygen delivery being overestimated.

This study was supported by the Swedish Heart and Lung Foundation and the Swedish Medical Research Council.
1 Kramer BL, Massie BM, Topic N. Controlled trial of captopril in chronic heart failure; a rest and exercise captopril in chronic heart failure; a rest and

2 Bussman WD, Storger H, Hadler D, Reifart N, Fassbinder $\mathrm{W}$, Jungmann $\mathrm{E}$, et al. Long-term treatment of severe chronic heart failure with captopril: a double-blind, randomized, placebo-controlled, long-term study $J$ Cardiovasc Pharmacol 1987;9(suppl 2):S50-60.

3 Sharpe DN, Murphy J, Coxon R, Hannan SF. Enalapril in patients with chronic heart failure: a placebo-controlled, randomized, double-blind study. Circulation 1984;70 271-8.

4 Eckardt KU, Bauer C. Erythropoietin in health and disease. Eur J Clin Invest 1989;19:117-27.

5 Fisher JW, Samuels AI, Langston JW. Effects of angiotensin and renal artery constriction on erythropoietin production. J Pharmacol Exp Ther 1967;157:618-25.

6 Gould AB, Goodman S, DeWolf R, Onesti G, Swartz C. Interrelation of the renin system and erythropoietin in rats. J Lab Clin Med 1980;96:525-34.

7 Fried W, Barone-Varelas J, Barone T, Anagnostuo A. Effect of angiotensin infusion on extrarenal erythropoietin of angiotensin infusion on extrarenal ext

8 Hirakata H, Onoyama K, Hori K, Fujishima M. Participa tion of the renin-angiotensin system in the captoprilinduced worsening of anemia in chronic hemodialysis. induced worsening of anemia
Clin Nephrol 1986;26:27-32.

9 Griffing GT, Melby JC. Enalapril (MK-421) and the white cell count and haematocrit [letter]. Lancet 1982;i:1361.

10 Patterson JA, Naughton J, Pietras RJ, Gunnar RM. Tread mill exercise in assessment of the functional capacity of patients with cardiac disease. Am J Cardiol 1972;30: 757-62.

11 Sahn DJ, DeMaria A, Kisslo J, Weyman A. Recommenda tions regarding quantitation in $M$-mode echocardiography: results of a survey of echocardiographic measurements. Circulation 1978;58:1072-83.

12 Jonsell S. A method for the determination of the heart size by teleroentgenography (a heart volume index). Acta Radiologica 1939;20:325-40.

13 Borg GAV. Psychophysical bases of perceived exertion. Med Sci Sports Exerc 1982;14:377-81.

14 Karlsson J, Jacobs I, Sjödin P, Tesch P, Kaiser P, Sahl O, et al. Semi-automatic blood lactate assay: experiences from al. Semi-automatic blood lactate assay: experiences from

15 Hallman H, Farnebo LO, Hamberger B, Jonsson G. A sensitive method for determination of plasma catecholamines using liquid chromatography with electrochemical detection. Life Sci 1978;23:1049-52.

16 Rustad H. Correction for trapped plasma in microhematocrit determinations. Scand J Clin Lab Invest 1964 16:677-9.

17 Holmgren A, Ekelund LG. Determination of total blood volume. In: Sjöstrand $\mathrm{T}$, ed. Clinical physiology. Stockholm: Svenska Bokforlaget, 1967:241-5.

18 Captopril Multicenter Research Group. A placebocontrolled trial of captopril in refractory chronic congestive heart failure. J Am Coll Cardiol 1983;2:755-63.

19 Cleland JGF, Dargie HJ, Ball SG, Gillen G, Hodsman GP, Morton JJ, et al. Effects of enalapril in heart failure: a double-blind study of effects on exercise performance,
renal function, hormones, and metabolic state. Br Heart $J$ 1985;54:305-12.

20 Cleland JGF, Dargie HJ, Hodsman GP, Ball SG, Robertson JIS, Morton JJ, et al. Captopril in heart failure: a doubleblind controlled trial. Br Heart J 1984;52:530-5.

21 Creager MA, Massie BM, Faxon DP, Friedman SD Kramer BL, Weiner DA, et al. Acute and long-term effects of enalapril on the cardiovascular response to exercise and of enalapril on the cardiovascular response to exercise and J Am Coll Cardiol 1985;6:163-7.

22 Franciosa JA, Wilen MM, Jordan RA. Effects of enalapril, a new angiotensin-converting enzyme inhibitor, in a controlled trial in heart failure. J Am Coll Cardiol 1985;5: 101-7.

23 McGrath BP, Arnolda L, Matthews PG, Jackson B, Jennings G, Kiat $\mathrm{H}$, et al. Controlled trial of enalapril in congestive heart failure. Br Heart $J$ 1985;54:405-14.

24 Mulligan IP, Fraser AG, Tirlapur V, Lewis MJ, Newcomb RG, Henderson AH. A randomized cross-over study of enalapril in congestive heart failure; haemodynamic and hormonal effects during rest and exercise. Eur $J$ Clin Pharmacol 1988;34:323-31.

25 Timmis AD, Bojanowski LM, Najm YC, Nelson DJ, Gosling RG. Captopril versus placebo in congestive heart failure: effects on oxygen delivery to exercising skeletal muscle. Eur Heart J 1987;8:1295-304.

26 Sinoway LI, Minotti JR, Davis D, Pennock JL, Burg JE, Musch TI, et al. Delayed reversal of impaired vasodilatation in congestive heart failure after heart transplantation. tion in congestive heart failure

27 Sullivan MJ, Higginbotham MB, Cobb FR. Exercise training in patients with severe left ventricular dysfunction: ing in patients with severe left ventricular dysfunction: 506-15.

Drexler H, Banhardt U, Meinertz T, Wollschläger H, Lehmann $M$, Just $H$. Contrasting peripheral short-term and long-term effects of converting enzyme inhibition in patients with congestive heart failure. A double-blind placebo-controlled trial. Circulation 1989;79:491-502.

29 Webster MWI, Fitzpatrick MA, Hamilton EJ, Nicholls MG, Ikram H, Espiner EA, et al. Effects of enalapril on clinical status, biochemistry, exercise performance and haemodynamics in heart failure. Drugs 1985;30(supp 1):74-81. 
30 Cohn JN, Mashiro I, Levine TB, Mehta J. Role of vasoconstrictor mechanisms in the control of left ventricular performance of the normal and damaged heart. $A m, J$ Cardiol 1979;44:1019-22.

31 Cleland JGF, Gillen G, Dargie HJ. The effects of frusemide and angiotensin-converting enzyme inhibitors and their combination on cardiac and renal haemodynamics in heart failure. Eur Heart $J$ 1988;9:132-41.

32 Fan FC, Chen RYZ, Schuessler GB, Chien S. Effects of hematocrit variations on regional hemodynamics and hematocrit variations on regional hemodynamics and
oxygen transport in the dog. Am J Physiol 1980;238: oxygen tran

33 Saltin B, Kiens B, Savard G, Pedersen PK. Role of hemoglobin and capillarization for oxygen delivery and extraction in muscular exercise. Acta Physiol Scand 1986; 128(suppl 556):21-32.

34 Onoyama K, Motomura K, Makita H, Kiyama S, Takata $Y$, Urabe A, et al. Effects of long-term captopril on angiotensin II and erythropoietin levels and recovery from hemorrhagic anemia in rats. Curr Ther Res 1987;41: 472-7.

35 Bauer C, Kurtz A. Oxygen sensing in the kidney and its relation to erythropoietin production. Annu Rev Physiol 1989;51:845-56.

36 Eckardt KU, Kurtz A, Bauer C. Regulation of erythropoietin production is related to proximal tubular function. Am J Physiol 1989;256:F942-7.

37 Hasking GJ, Esler MD, Jennings GL, Dewar E, Lambert G Norepinephrine spillover to plasma during steady-state Norepinephrine spillover to plasma during steady-stat
supine bicycle exercise. Circulation 1988;78:516-21.

38 Osborn JF, Johns EJ. Renal neurogenic control of renin and prostaglandin release. Miner Electrolyte Metab 1989;15: 51-8.

39 Ichikawa I, Kon V, Pfeffer MA, Pfeffer JM, Brenner BM. Role of angiotensin II in the altered renal function of heart failure. Kidney Int 1987;31:S213-5.

40 Cleland JGF, Dargie HJ. Heart failure, renal function, and angiotensin converting enzyme inhibitors. Kidney Int 1987;20:S220-8.
41 Hall JE. Control of sodium excretion by angiotensin II: intrarenal mechanisms and blood pressure regulation. $\mathrm{Am}$ $J$ Physiol 1986;250:R960-72.

42 Fyhrquist F, Karppinen $K$, Honkanen $T$, Saijonmaa $O$, Rosenlöf $\mathrm{K}$. High serum erythropoietin levels are normalized during treatment of congestive heart failure with enalapril. J Intern Med 1989;226:257-60.

43 Antonnacio MJ, Kerwin L. Evidence for prejunctional inhibition of norepinephrine release by captopril in inhibition of norepinephrine release by captopril in 68:209-12.

44 McGrath BP, Arnolda LF. Enalapril reduces the catecholamine response to exercise in patients with heart failure. Eur J Clin Pharmacol 1986;30:485-7.

45 Packer M, Lee WH, Medina N, Yushak M, Kessler PD. Functional renal insufficiency during long-term therapy with captopril and enalapril in severe chronic heart failure. Ann Intern Med 1987;106:345-54.

46 Giles TD, Katz R, Sullivan JM, et al. Short-and long-acting angiotensin-converting enzyme inhibitors: a randomized trial of lisinopril versus captopril in the treatment of congestive heart failure. J Am Coll Cardiol 1989;13: $1240-7$.

47 Kubo S, Nishioka A, Nishimura H, Kawamura K, Takatsu $T$. Effects of captopril on arterial and venous pressure, renal function and humoral factors in severe chronic renal function and humoral factors in severe chronic 1984;36:456-63.

48 Dzau VJ, Hollenberg NK. Renal response to captopril in severe heart failure: role of furosemide in natriuresis and severe heart failure: role of furosemide in natriuresis and reversal $777-82$.

49 Mujais SK, Fouad FM, Textor SC, Tarazi RC, Bravo EL Hart $\mathrm{N}$, et al. Transient renal dysfunction during initial inhibition of converting enzyme in congestive hear failure. Br Heart J 1984;52:63-71

50 Fouad FM, Tarazi RC, Bravo EL, Hart NJ, Castle LW, Salcedo EE. Long-term control of congestive heart failure with captopril. Am J Cardiol 1982;49:1489-96. 